\title{
Social reproduction of generations in the face of digital challenges
}

\author{
Oleg Sirotkin ${ }^{1 *}$, Raisa Chumicheva ${ }^{2}$, Irina Kulikovskaya ${ }^{2}$, and Liudmila Kudinova ${ }^{2}$ \\ ${ }^{1}$ Don State Technical University, 344003, Rostov-on-Don, Russia \\ ${ }^{2}$ Southern Federal University, 344007, Rostov-on-Don, Russia
}

\begin{abstract}
The article describes the global processes that are transforming the world (migration and integration processes, inclusive education, digitalization of education, socio-psychological gap between generations, etc.). Global tendencies have changed the social space of people's life "cultural gaps", "social bottom", "spiritual crisis of parent-child relations and intergenerational ties", etc. have appeared, as modern challenges of society, affecting the social reproduction of generations. The problem of social reproduction, the significance of which is associated with the need for the development of sociality, the construction of the social world in the event chronotope, has been actualized; preservation of the social and historical memory of the people, the self-identity of the national community, the "core" of the spiritual image of the nation, etc. A powerful challenge in modern society is digitalization, which has changed the forms of communication and social roles, created a new virtual space for selfpresentation, self-expression, while the risk is the loss of cultural identity, blurring the lines between generations, etc. The article presents the mechanisms of integration of traditional and digital technologies of social reproduction of generations, the difference of which lies in the actualization of children's interest in the historical and cultural values of the people, in the organization of joint activities to create virtual historical museums, etc. Social reproduction of generations is a complex and longterm process, the success of which depends on the unity of activities in the professional, parenting and children's community.
\end{abstract}

\section{Introduction}

Social reproduction of generations faces up a number of modern global challenges (migration and integration processes, inclusive education, digitalization of education, multinational and social multipolarity of society, socio-psychological generation gap, etc.). Social reproduction of generations is associated with the need of an individual to develop socially, shaping one's social identity, i.e. awareness of oneself as a member of society, an active participant who is ready to interact with it and other people; meaningfully following the norms of social life; ability to actively share social values, their development and creation. Social reproduction also relates to constitution of social world view in terms of the event-based chronoscope: preservation of social and historical memory of the people (the

*Corresponding author: ol.sirotkin2010@yandex.ru 
transfer of self-identity of the national community, the "core" of the spiritual image of the nation, the "national genetic code" that stores information about the history, development stages, conditions of existence and ethnic potential of the nation); the search for latent mechanisms of social reproduction.

\section{Challenges of Digitalization for Social Reproduction of Generations}

Digitalization has changed the usual forms of communication and social roles, brought about new digital communication and interaction forms (forums, chats, blogs, online games, and social networks) which have undoubtedly changed the processes of socialization of children and adolescents, development of their cultural and individual identity. Digitalization has created the virtual space, a specific virtual platform for self presentation, dating, information exchange, conflict resolution and creativity.

Virtual space has dramatically changed the value system of children who want to write their own life story, leaving a digital footprint in this space. E.L. Soldatova, D.N. Pogorelov define a characteristic feature of virtual space as a contradiction between the motivation for self-actualization and personal development in accordance with the normative criteria of social expectations, the need to preserve personal integrity and certain alignment [1]. This requires the search for new socialization content and technologies that determine the balance between traditional means of socialization and digital ones.

Virtual space, where children and adolescents spend a lot of time, gradually begins to form a new type of information behavior of the growing generation which is manifested by a system of digital ways of navigating the Internet space; confident use of tools for information search - a tablet, the Internet, digital platforms, etc.; the need to present themselves in the digital setting. The virtual space provides emergence of a new way of information behavior that reflects the information worldview of children and adolescents; operating with social information, mastering new skills of self-regulation and self-analysis of their own information field and information behavior [2]. Virtual space acts as a medium and a degree of "meeting the needs of information communication participants, the level of creativity, collection, storage, processing and transfer of information, and at the same time as an activity aimed at optimizing all types of information-mediated communication, creating the most favorable conditions for the values of culture to be mastered by a person, to enter harmoniously into the way of life" [3]. Virtual space creates the environment appropriate for independent information acquisition, understanding it in the context of culture and applying information in one's daily life; development of a person who is able to think independently, self-actualize and adapt socially to the rapidly changing world [4].

In this respect, it is worth mentioning that it is the virtual space that creates wide opportunities for transferring communication from the real setting to the imaginary game environment where a child easily creates a new image of the generation that actively manifests itself in the digital space, but faces certain problems in the real-life social space. In her research, O.A. Maksimova emphasizes another feature of the virtual space, i.e. emergence of new forms of interaction (chats, blogs, online games) which branch from social networks and form individual identity, while erasing cultural and social identity [4]. Individual identity can act as a factor that diminishes team values, leveling team success. Loss of team spirit in the digital environment can lead to civilizational disasters since disunity of people in society will not enable to maintain the balance between the world of nature, technology, and mankind, preserve the universal experience, traditions and values accumulated by the previous generation that lay the socio-cultural foundation for the next generation. 
It is necessary to agree with the opinion of scientists that it is high time to carry out longitudinal study into the patterns of cognitive development of a modern digital child, his/her value implications that determine social behavior, ability to recognize the emotions and feelings of another person, features of "language acquisition and speech development, socio-semiotic codes in the process of communication in the information environment" [5].

\section{Digitalization and its Risks in the Social Reproduction of the Generations}

The digital environment implies not only social effects, but also risks as factors of development and individual behavior regulators. The emergence of new models of social behavior among the younger generation in the virtual space determines the life of the growing generation, success in activities and the future development of civilization. Digitalization sets forth individual skills as personal values and causes shift of emphasis from the team spirit (unity in Christianity, collectivism in the Soviet school, corporatism in project activities) to individualism which can indirectly or directly lead to children aggressiveness, cruelty, envy, bullying, etc. Chats act as a digital setting for public virtual space where social conflicts between children are not rare. It is important to teach the child not to be afraid of risks, to overcome social rejection and discover ways to solve emerging problems in the limitless information environment.

The digital environment can be dangerous with the emergence of risky activities that affect mental, physical, and social health of a child and even pose threat to his/her life. According to A.Yu. Gubanova, "a risky activity" can also create problems of national, social and psychological security of the child's personality and society [6]. Among risky activities, a child or a teenager may have computer addiction which can widen the gap between the generations of children and parents and decrease the authority role of a parent in child-parental relations.

Virtual space leads to lower interest to real face-to-face communication with peers and parents, growing fatigue and irritability, weakened volitional regulation and an increase in the number of children with hyperactivity. Children's fascination with online communication pose the danger of forgetting what friendship means in the real world, losing identity which is formed through rituals, values, customs and getting used to new virtual ways of life (pandemic); it also reduces the amount of time spent by a child with parents and peers [7]. However, digital media (smartphone, iPad, tablet, etc.), as noted by G.U. Soldatova, E. I. Rasskazova, T.A. Nestik, notes, refer to cultural tools that contribute to generation of other cultural practices, phenomena, meanings and notions different from traditional ways which, in complex interaction with traditional offline life activities, create a special social situation of development and a new way of life of a modern child [7].

\section{Mechanisms of Social Reproduction of Generations}

"Under the influence of globalization processes in the modern world, digital technologies are spreading in no time" states A.A. Lisenkova [8]. Civilizational processes that have determined the development of digital technologies require the search for new mechanisms of social reproduction of future generations. The integration of traditional socialization technologies and innovative digital means of social reproduction of generations can be identified as a new mechanism (see Table 1).

Table 1. Traditional and digital means of social reproduction of generations. 


\begin{tabular}{|l|l|}
\hline $\begin{array}{c}\text { Social content of traditions, literary } \\
\text { texts, visual images, social actions }\end{array}$ & $\begin{array}{l}\text { Videos of social behavior and comparative } \\
\text { analysis }\end{array}$ \\
\hline $\begin{array}{c}\text { Interiorization of values - freedom, } \\
\text { understanding, awareness of common } \\
\text { interests and goals, mutual assistance - } \\
\text { as personal meanings into socially } \\
\text { significant activities }\end{array}$ & $\begin{array}{l}\text { Videos of socially-oriented activities of } \\
\text { children and children's reflection on their } \\
\text { activities }\end{array}$ \\
\hline $\begin{array}{l}\text { Eventful situations - socio- } \\
\text { communicative rituals, rules of } \\
\text { teamwork }\end{array}$ & $\begin{array}{l}\text { Computer-assisted graphic design of event- } \\
\text { driven situations and dialogue about the } \\
\text { positions of communicants }\end{array}$ \\
\hline $\begin{array}{l}\text { Models of human behavior - legendary } \\
\text { human history, patterns of social reality, } \\
\text { literary characters, etc. }\end{array}$ & $\begin{array}{l}\text { Computer simulation of social behavior in } \\
\text { the 3D format and transfer to another iconic } \\
\text { system (image, graphics, 3D mini sculptures, } \\
\text { etc.) }\end{array}$ \\
\hline $\begin{array}{c}\text { Places of memory - memorials, } \\
\text { museums, places of performances, } \\
\text { carnivals, etc. }\end{array}$ & $\begin{array}{l}\text { Virtual museums, carnivals and finding } \\
\text { one's place in them, defining a personal social } \\
\text { position }\end{array}$ \\
\hline $\begin{array}{c}\text { Diagrams that give outline to the field } \\
\text { of human life and activity, highlight the } \\
\text { core of the social world view }\end{array}$ & $\begin{array}{l}\text { Computer games and reproduction of game } \\
\text { situations in real and gaming relationships }\end{array}$ \\
\hline $\begin{array}{c}\text { Ideogram - metaphorical (symbolic) } \\
\text { form of human interaction, respectively, } \\
\text { a particular social position, social- } \\
\text { oriented activities, social situations }\end{array}$ & $\begin{array}{l}\text { Computer simulation of interaction in the } \\
\text { independently found format (picture, diagram, } \\
\text { sequence, etc.) }\end{array}$ \\
\hline $\begin{array}{l}\text { Signs of taboo forms of } \\
\text { communication and positive social } \\
\text { behavior }\end{array}$ & $\begin{array}{l}\text { Independent Internet search (a computer } \\
\text { game, cartoon, kids movie, etc.) of taboos and } \\
\text { advantages in communication and developing } \\
\text { attitude towards them }\end{array}$ \\
\hline $\begin{array}{l}\text { Matrix of communications, sociocode } \\
\text { (communication algorithm) in one's } \\
\text { future }\end{array}$ & $\begin{array}{l}\text { Digital crossword puzzle and computer } \\
\text { graphic modeling of sociocode in the future } \\
\text { (ways of communication in mastering values, } \\
\text { becoming a part of the society, etc.). }\end{array}$ \\
\hline
\end{tabular}

Teachers have to master new digital competencies of social reproduction of a new generation, to encourage children and adolescents to reflect on and critically assess social models, behavior and communication patterns $[9,10]$. A number of foreign authors draw attention to the fact that it is necessary to look for ways to preserve physical and social health of children in the digital environment in order to avoid all possible risks of personal development. On the other hand, the authors argue that digital technologies affect the cognitive, speech, and social aspects of a personality $[11,12,13,14]$.

\section{Methods and Results of Diagnostic Research}

The approbation of traditional and digital means in the process of solving the problems of socialization of primary schoolchildren made it necessary to conduct primary diagnostics (at the beginning and end of the academic year) of the criteria characterizing the effectiveness of socialization of students. The criteria were identified:

- understanding of basic social values (life values);

- ideas about good and evil, happiness, purpose and meaning of life; universal values (universal values);

- life, health, personal safety, well-being, family, education, law and order, Motherland; the values of interpersonal communication (interpersonal values);

- honesty, selflessness, benevolence, friendship), reflected in the context of literary works, places of memory (historical museum), human stories (one's family); 
- choice of means of communication (verbal - dialogue, contract, beliefs; non-verbal facial expressions, emotional reactions, gestures) in a real format of communication (in a social situation, in teamwork) and in a digital format (computer games, computer modeling of the communication algorithm);

- correspondence of the assessments of the perceived model of social behavior (the hero of a literary work), the model of social behavior in the future (the created project of the model of behavior in a situation), the model of real social behavior (one's behavior in a social situation).

The designated criteria for the analysis of the results of the manifestation of the social experience of primary schoolchildren were studied by the method of value orientations by M. Rokich, by the method of studying the communicative abilities of G.A. Zuckerman "Who is right", D. Stott's observation map, "Unfinished sentences" (methodology of L.M. Shipitsyna).

The revealed quantitative data based on the research results show the specifics of understanding social values in various contexts and orientation towards them in real social behavior (see Fig. 1, 2, 3).

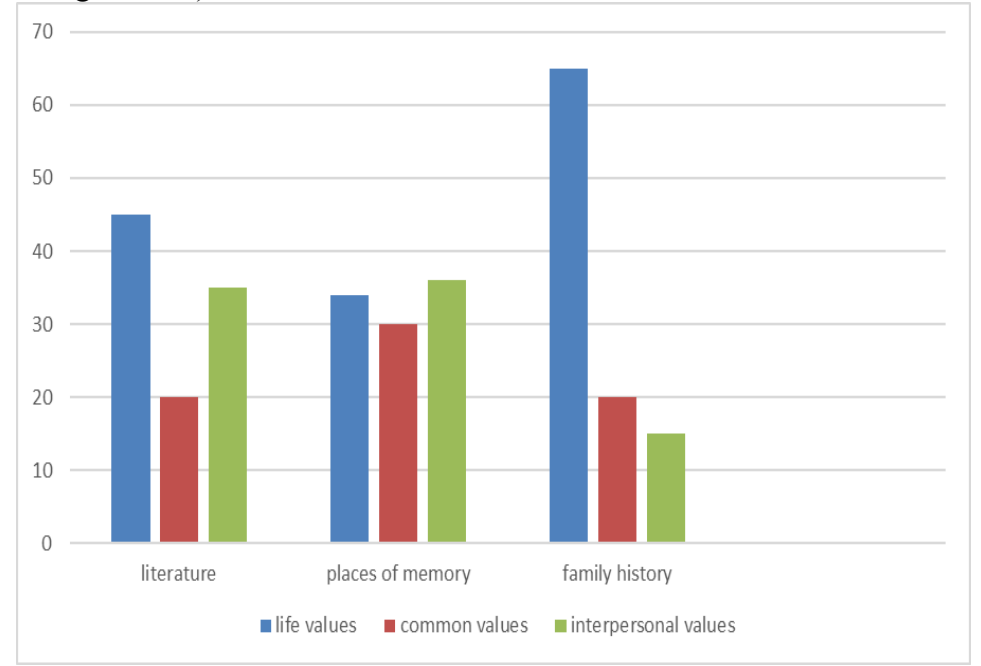

Fig. 1. Features of understanding social values junior schoolchildren.

Qualitative analysis of the data makes it possible to establish that life values (ideas about good and evil, happiness, purpose and meaning of life) are understood by primary schoolchildren mostly precisely, which is associated with their personal social experience, the nature of parent-child relationships, parental attitudes addressed to children; universal values (life, health, personal safety, welfare, family, education, law and order, homeland) are actualized to a greater extent in places of memory and in the family, which may be due to the active position of parents in raising a child; the values of interpersonal communication are actualized and demanded to a greater extent by the child in the peer community, therefore they become significant for him personally (honesty, disinterestedness, benevolence, friendship), and are also supported in family stories. In the manifestation of these values by family members. 


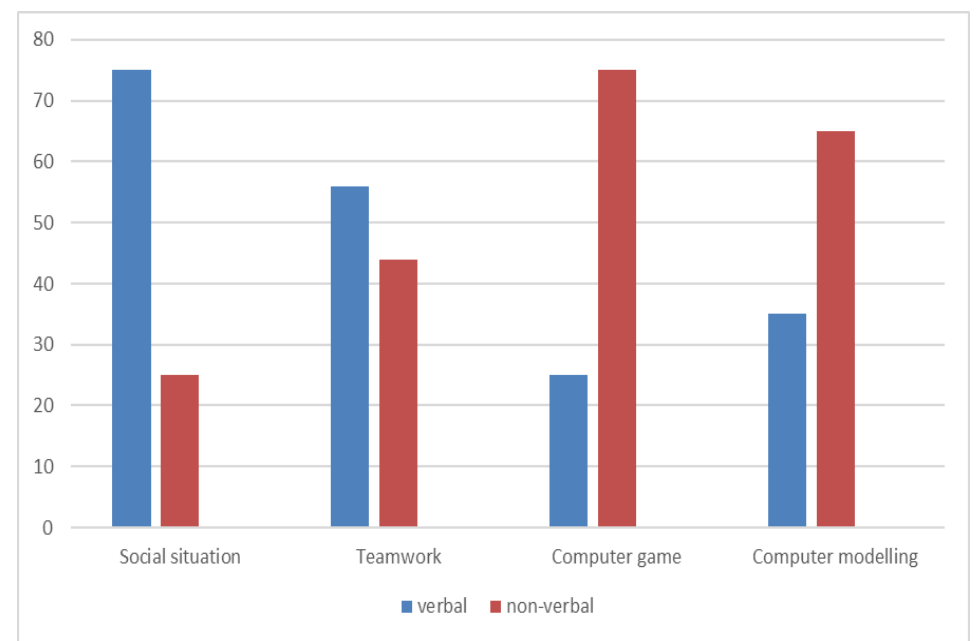

Fig. 2. Features of the choice of junior means of communication in various situations.

The creation of various situations for the choice of communication means for junior schoolchildren made it possible to establish that, in most cases, primary school students give their preferences to a computer game, play independently with great interest and for a significantly long time (from 1 hour to 1.5 hours). Computer games and modeling evoke a variety of emotions and reactions; to a lesser extent, children want to interact with someone. The students asked for the help of an adult in situations of difficulty in modeling educational computer situations. In real situations of communication and team activity, junior schoolchildren to a greater extent chose verbal means of communication, showed the need to prove and discuss their position, tried to come to an agreement in conflict situations. It has been found that primary school students are able to regulate their behavior from the peer community - to restrain negative emotions, not to show aggressive behavior patterns, and to show the need to convince. If someone is, wrong or not fair.

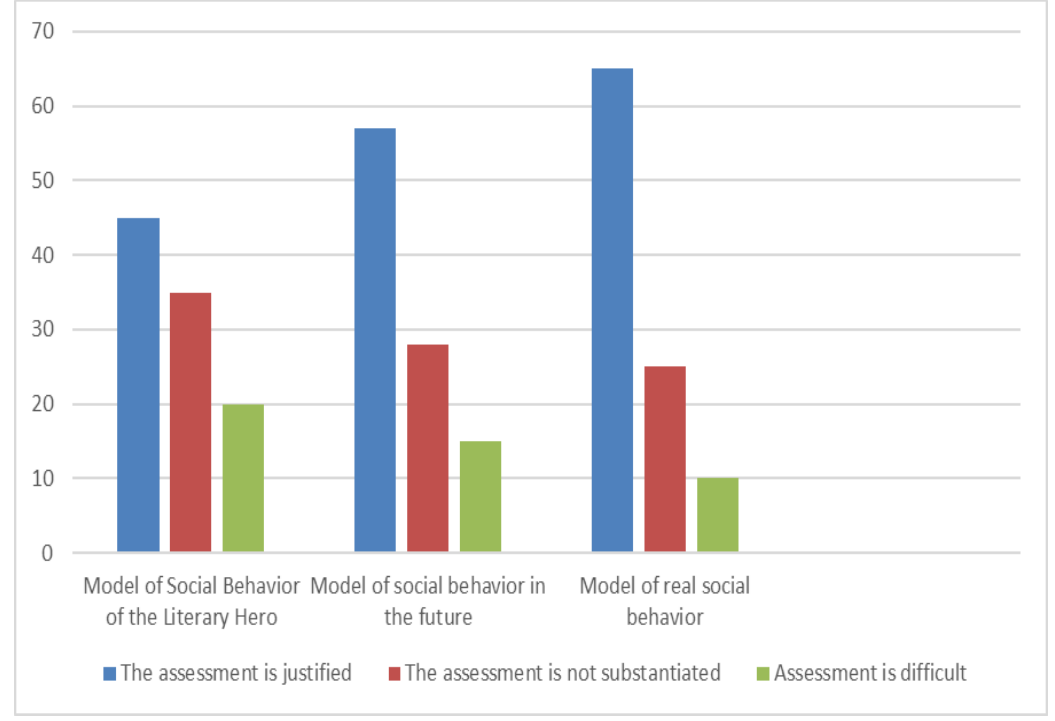

Fig. 3. Features of assessments of behavioral models by younger schoolchildren.

Comparing the assessments of models of social behavior of various subjects (a literary hero, a future model of their own behavior, their real behavior in the present tense), given 
by younger students when analyzing various models, it was established that primary school students cannot yet give reasonable and detailed assessments of social behavior in various models, which is connected, on the one hand, with the generalized nature of value assessments, and on the other hand, with the level of speech development and the development of critical thinking; on the other hand, it is positive that students strive to understand the reasons for their social behavior in certain situations, to give objective assessments of the chosen model of behavior in the community of peers and adults.

Social reproduction of the new generation is carried out at the present stage in a situation of transformation of the global world. It is significant as a human resource for any state in ensuring a civilized way of development of society. The sustainability of the development of the civilized world will depend on what values the new generation will choose. In pedagogical science, the search for new mechanisms of social reproduction of a new generation, born in an era of massive digitalization of society, is carried out. Primary diagnostics of the ideas of junior schoolchildren about values, the choice of means of communication, assessment of models of behavior in various situations of communication allows us to state that students still have an interest and need for means of communication in real situations and activities. Approbation of the mechanisms of social reproduction of a new generation on the principle of integration of traditional national and universal (universal) values and digital means will preserve the national aspect of education and open up wide opportunities for social self-realization and individualization of the student in an open virtual space.

\section{Conclusion}

It is important to teach children to create an individual digital event feed, new content streams, sweepstakes, and challengers, while not separating the real and virtual world, but developing ways to learn about the social world by digital means. It is important to foster children's abilities to learn about the social world by digital means; to support children's interest in a real person, not a game character; to teach them to reflect on their social image as a representative of the new generation; "to help young people in setting the right priorities and finding appropriate behavior patterns in the digital environment" [15].

Teachers are to find ways to supporting interests and motives of children to personal identity, people's relationships, and self-cognition of their social image as future representatives of the growing generation. Teachers need to learn how to work in new social challenges, creating the digital territory for the child to reach social success and effective dialogue in professional, parental and children communities.

\section{References}

1. E. L. Soldatova, D. N. Pogorelov, Education and science 20 (5), 105-121 (2018).

2. T.V. Kalinina, Content and methods of forming the foundations of information culture in senior preschoolers (monograph, Moscow State Pedagogical University, Moscow, 2019).

3. G.U. Soldatova, Social Psychology and Society 9 (3), 71-80 (2018).

4. O.A. Maksimova, Bulletin of the Chelyabinsk State University 22 (313), 6-10 (2013).

5. N.N. Koroleva, S.N. Tseitlin, Yu. L. Project, Universum, Bulletin of the Herzen University 4, 91-98 (2013).

6. A.Yu. Gubanova, Bulletin of the RSUH. Series "Philosophy. Sociology. Art History" 2 (4), 92-97 (2016). 
7. G.U. Soldatova, T.A. Nestik, E.I. Rasskazova, E.Yu. Zotova, Internet Development Fund Moscow (2013).

8. A.A. Lisenkova, Russian Humanitarian Journal 3, 217-221 (2018).

9. S. Didaa, H. Hafiarb, A.L. Kadiyonoc, S. Lukman, Gender, education, and digital generations as determinants of attitudes toward health information for health workers in West Java (Indonesia). DOI: https://doi.org/10.1016/j.heliyon.2021.e05916.

10. D. Jiang, L.J. Zhang, Computers \& Education 150, 103841 (2020). DOI: https://doi.org/10.1016/j.compedu.2020.103841.

11. B. King, E.K. Fishman, S.P. Rowe, Journal of the American College of Radiology 18 (3), 341-464 (2021). DOI: https://doi.org/10.1016/j.jacr.2020.05.031.

12. Bettina Perregaard, Language \& Communication 62, Part A, 1-82 (September 2018). https://doi.org/10.1016/j.langcom.2018.06.001.

13. Steffen Roth, Harry F. Dahms, Frank Welz, Sandro Cattacin, Technological $\begin{array}{llll}\text { Forecasting and Social Change 149, } & \end{array}$ https://doi.org/10.1016/j.techfore.2019.119778.

14. Greg Oulahen, Geoforum 119, 1-298 https://doi.org/10.1016/j.geoforum.2020.12.021.

15. Asta Cekaite, Linguistics and Education 59, October 2020, 100753. 